\title{
Study the Addition of Lab-Made Gas Mixing Unit with Varying of Inter-Electrode Distances on the Characterization of DC Magnetron Sputtering System
}

\author{
Bahaa T. Chiad1, Firas J. Kadhim¹, Ahmed A. Anber ${ }^{2 *}$ \\ ${ }^{1}$ Department of Physics, College of Science, University of Baghdad, Baghdad, Iraq \\ ${ }^{2}$ Department of Physics, College of Science, University of Wasit, Wasit, Iraq \\ Email: *ahmedkrm88@gmail.com
}

How to cite this paper: Chiad, B.T., Kadhim, F.J. and Anber, A.A. (2017) Study the Addition of Lab-Made Gas Mixing Unit with Varying of Inter-Electrode Distances on the Characterization of DC Magnetron Sputtering System. Open Access Library Journal, 4: e3269.

http://dx.doi.org/10.4236/oalib.1103269

Received: November 30, 2016

Accepted: January 3, 2017

Published: January 6, 2017

Copyright $\odot 2017$ by authors and Open Access Library Inc.

This work is licensed under the Creative Commons Attribution International License (CC BY 4.0).

http://creativecommons.org/licenses/by/4.0/

\begin{abstract}
In this paper, the effect of lab-made gas mixing unit and inter-electrode distance on, current-voltage characteristics of argon and argon-nitrogen plasma, Paschen's curve and variation of discharge current with working pressure are presented. The results showed the mixing of nitrogen gas with argon at ratio $\operatorname{Ar}: \mathrm{N}_{2}$ of 1:1, an increase in the discharge current was observed, while at ratio Ar: $\mathrm{N}_{2}$ of 2.5:1 which increases the discharge current at the distance of $7.5 \mathrm{~cm}$. Paschen's curves have been showed, it is clear that the breakdown voltage $V_{B}$ increases as nitrogen gas percentage $50 \%$. This effect is due to, the additional energy loss channel nitrogen gas such as vibration, rotational and molecular dissociation. The discharge current was varied by changing the working gas pressure. With increasing of working gas pressure, which is attributed to more molecules which are available for the electrons to collide with and to generate a new free electron and a positive ion and so making the DC voltage more negative. The discharge current is decreasing with increasing gas pressure above 3 mbar. The relation was plotted at certain discharge voltage of $600 \mathrm{~V}$ and three certain distances between the electrodes of $(2.5,4.5$ and $7.5 \mathrm{~cm})$.
\end{abstract}

\section{Subject Areas}

Plasma

\section{Keywords}

Gas Discharge, Breakdown Voltage, Paschen’s Law, DC Magnetron Sputtering 


\section{Introduction}

The DC glow discharges have been extensively used in the gas laser, material processing [1] and thin film deposition [2]. Therefore, the research into the conditions of the glow discharge breakdown is of considerable interest. Gas discharge breakdown is a complex process which generally begins at electronic avalanche. A gas in its normal state is almost a perfect isolator. Various phenomena occur in gaseous dielectrics when a voltage is applied. When the applied voltage is low, small currents flow between the electrodes and the insulation retains its electrical properties. On the other hand, if the applied voltages are large, the current flowing through the insulation increases very sharply, and an electrical breakdown occurs [3].

As far as it is known, the breakdown curves of the glow discharge are described by Paschen's law $V_{B}=f(p d)$; i.e. the breakdown voltage depends on the electrode distance $(d)$ and the gas pressure $(p)$ [4]. Primary electronic ionization occurs prior to cascade ionization. Townsend introduced a coefficient $\alpha$ known as Townsend's first ionization coefficient and is defined as the number of electrons produced by an electron per unit length of path in the direction of field. Once the Townsend ionization coefficient becomes sufficiently high along with the intensification of electric field, current will transfer from non-selfmaintained to self-maintained process, that is, electric breakdown occurs. The first Townsend's coefficient, which depends on the gas type and gas pressure, as well as on the electric field $E$ in the inter-electrode space, can be expressed following Townsend theory as:

$$
\frac{\alpha}{B}=A \exp \left[-\frac{B P}{E}\right]
$$

where $A$ and $B$ are normally determined experimentally and have been found to be relatively constant for a given gas over a range of fields and pressures. It is more convenient to use the ionization coefficient $\eta$ (or ionization efficiency) defined as the number of ionization events caused by an electron in passing through a potential difference of one volt [5]:

$$
\eta=\alpha / E
$$

This quantity depends only on the reduced electric field $E / P$. The experimental data are usually presented either in the form $(E / P)$. Next, attention is turned to the consequences of the subsequent motion of the positive ions. Acceleration of the positive ions in the electric field leads, in principle, to secondary emission of electrons from the negative electrode, when they reach there, at a rate of $\gamma$ electrons per incident ion [6] is known as the effective secondary electron emission coefficient, or second Townsend coefficient $\gamma$. Additionally to $\alpha$ it is an important parameter in the Townsend regime and it depends on the electrode material and on the nature of the filling gas used. The secondary ionization coefficient is related to that of Townsend's first ionization coefficient $\alpha$, and by using Equation (6), this dependence can be expressed in terms of the ionization coefficient $\eta[5][7]$ : 


$$
\gamma=\frac{1}{e^{\eta V B}-1}
$$

Thus, $\gamma$ depends on the cathode material and gas type, as well as on the ratio $E / P$ [8]. Gas discharge breakdown voltage $\mathrm{VB}$ is the minimum voltage required for initial breakdown of discharge. Before Townsend proposed the gas discharge breakdown theory, Paschen has found through experiment the function between gas discharge breakdown voltage and the product of gas pressure $(p)$ and cathode-anode distance $(d)$, following is the Paschen law expression of Townsend discharge [9]:

$$
V b=\frac{B p d}{\ln \left[\text { Apd } / \ln \left(1+\frac{1}{y}\right)\right]}=f(p d)
$$

The existence of a minimum breakdown voltage in Paschen's curve may be explained as follows: For values of $\mathrm{pd}>(\mathrm{pd}) \mathrm{min}$, electrons crossing the gap make more frequent collisions with gas molecules than at (pd)min, but the energy gained between collisions is lower. Hence, to maintain the desired ionization more voltage has to be applied. For $\mathrm{pd}<(\mathrm{pd}) \mathrm{min}$, electron may cross the gap without even making a collision or making only less number of collisions. Hence, more voltage has to be applied for breakdown to occur [3] [10]. When the external voltage is raised to a certain degree, discharge mode turns into glow discharge or spark discharge and the conversion process is breakdown. The inter-electrode voltage needed for the transition from non-self-sustaining discharge to self-sustaining discharge is called ignition voltage or breakdown voltage, and this is an important parameter of gas discharge device.

Through measuring the relationship between the ignition voltage and breakdown distance and gas pressure Paschen discovered a law that: the homogeneous field will be formed between the inter-electrodes after applying DC voltage to the two parallel plate electrodes. The inter-electrode distance is made as $\mathrm{d}(\mathrm{mm})$ and pressure is $\mathrm{p}(\mathrm{Pa})$, if gas components and electrode stuff are assured, and the gas is homoiothermal, then ignition voltage $\mathrm{Ub}$ is a function of pd instead of the two variables: $p$ and $d$, under the cold electrode condition, and Ub have a mini-mum Ubmin when the numerical value of pd is changed. Later, the law is called Paschen's Law [11].

\section{Experiment}

The magnetron sputtering system used in this work was designed to include vacuum chamber, discharge electrodes and magnetron assembly, vacuum unit, dc power supplies, gas mixer unit, cooling system, heating system, monitoring camera and measuring instruments. The system is schematically shown in Figure 1. The gas mixer was constructed from stainless steel. It contain of three cylinders each of $8 \mathrm{~cm}$ in diameter, and $20 \mathrm{~cm}$ in height. The gauges have been joined on the top of two cylinders consist of very precise valve to mix the gases perfectly, except the middle one which is $30 \mathrm{~cm}$ in height which mix a gases inside it. The purpose of gas mixer is to perform high precision control on mixing 


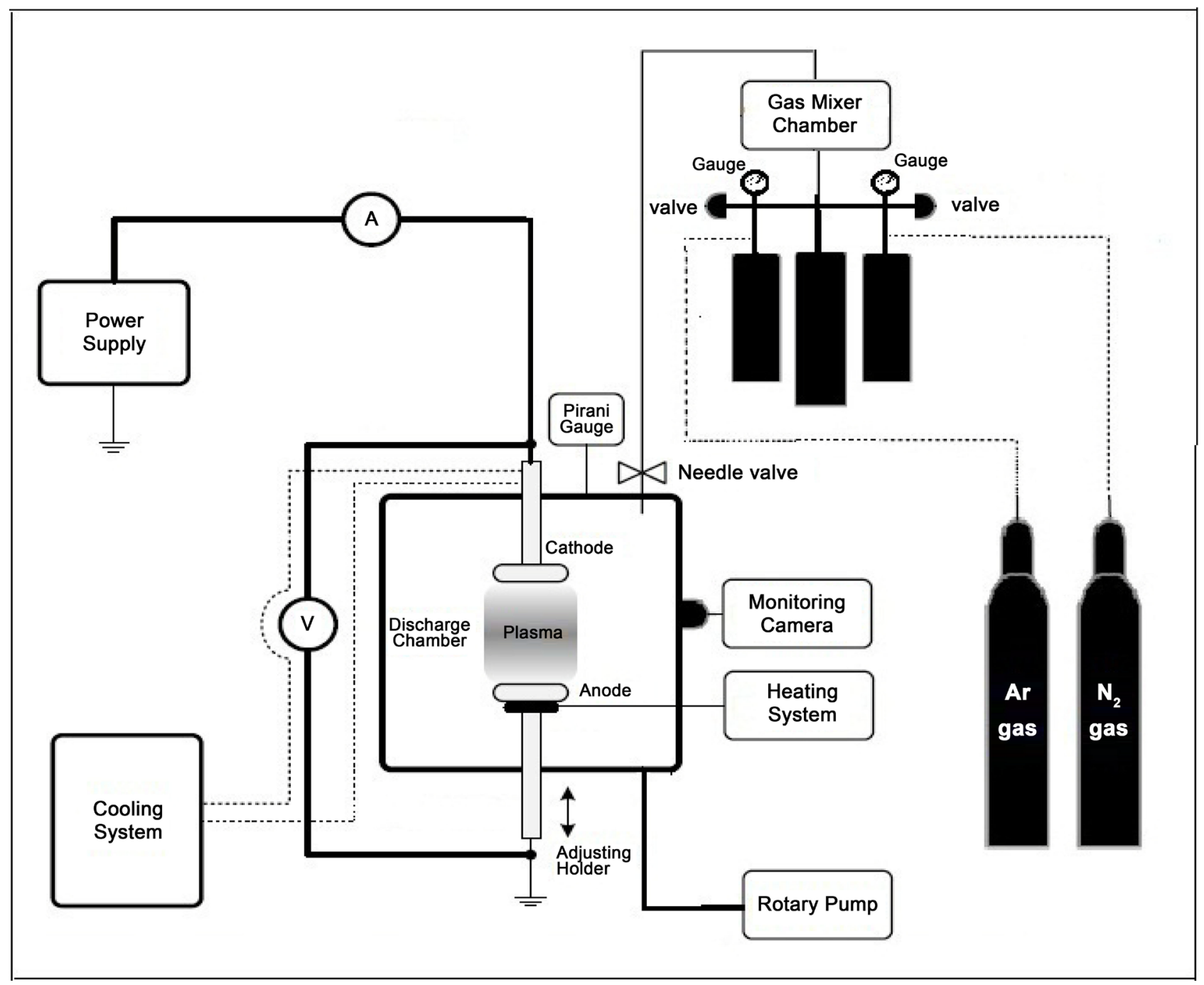

Figure 1. Schematic diagram of the system used in the present work.

ratios of $\mathrm{Ar}, \mathrm{N}_{2}$ and Figure 2 shows the gas mixing unit. Two discharge electrodes (anode and cathode) were designed and made of stainless steel (St. St. 304). The cathode consist of hollow disk of $80 \mathrm{~mm}$ in diameter and $8.5 \mathrm{~mm}$ in thickness. The electrode was joined to holder of $295 \mathrm{~mm}$ in length and outer and inner diameters of $16.2 \mathrm{~mm}$ and $11.6 \mathrm{~mm}$, respectively, to include a stainless steel channel of $78.5 \mathrm{~mm}$ in length and $5.6 \mathrm{~mm}$ in diameter through which the cooling water was flowed to the inside volume of the electrode. The holder tube includes a $1 \mathrm{~mm}$-step screw thread of $25.88 \mathrm{~mm}$ in length to connect the cooling channel tightly. The anode consist of disk of $90 \mathrm{~mm}$ in diameter and $6.5 \mathrm{~mm}$ in thickness. It was possible to heat the anode up to $350^{\circ} \mathrm{C}$ using controlled heating system. The distance between electrodes can be varied in range of $(2.5-7.5 \mathrm{~cm})$. In this work the magnetic field generated behind the cathode. The magnetic field was provided, firstly, by using the ring magnets. The magnetic field, was 4500 gauss. To ensure a minimal concentration of uncontrolled contaminations during the experiments, a double stage rotary pump (Edward $8 \mathrm{~m}^{3} / \mathrm{h}$ ) operating to a base pressure of about $3 \times 10^{-2}$ mbar was used. The pressure was monitored with 


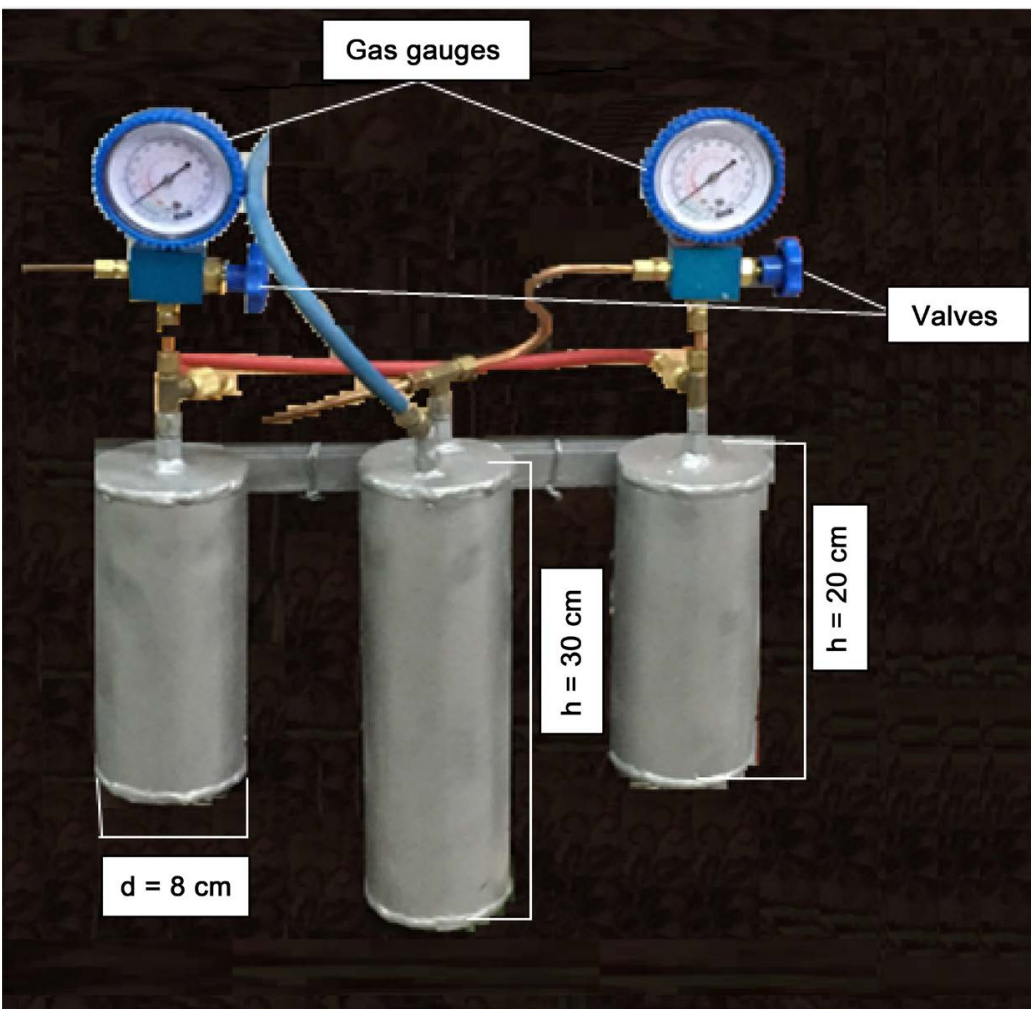

Figure 2. The lab-made gas mixer unit.

a pirani gauge with Edward controller (1105) was necessary to install in the plasma chamber in order to monitor actual pressure there and the partial pressure of discharge gases. The applied voltage was controlled by high voltage DC power supply $(0-1400 \mathrm{~V})$. In this work, the effects of gas mixer unit and interelectrode distance on breakdown voltage in low pressure of argon and argon-nitrogen mixture are studied.

\section{Results and Discussion}

The value of the voltage $V$ across the plasma chamber, is a highly nonlinear function of the current, $I$ (charge flow), down through the chamber. This is shown in Figure 3. The discharge current was measured as a function of discharge voltage at different inter-electrode distances $(2.5-7.5 \mathrm{~cm})$ without magnetron. When the voltage is $150 \mathrm{~V}$ to $200 \mathrm{~V}$ that no current flows. At voltages 200 - 250, discharge current initiates as the breakdown voltage is reached. Obviously, discharge current flows at smaller distance between the electrodes as the charge carriers (electrons) have to pass shorter distance to transfer from cathode to anode.

Also, the discharge current was measured as a function of inter-electrode distance as shown in Figure 4. It is clear, the current slightly increases at distance from 2.5 to $3.5 \mathrm{~cm}$, but decreases at distance of $4.5 \mathrm{~cm}$, obviously increases at distance of $5.5 \mathrm{~cm}$, and decreases at distance of $6.5 \mathrm{~cm}$ and $7.5 \mathrm{~cm}$. The behavior between discharge current and discharge voltage is nonlinear. At certain interelectrode distance (e.g., $2.5 \mathrm{~cm}$ ), the discharge current increases with increasing 


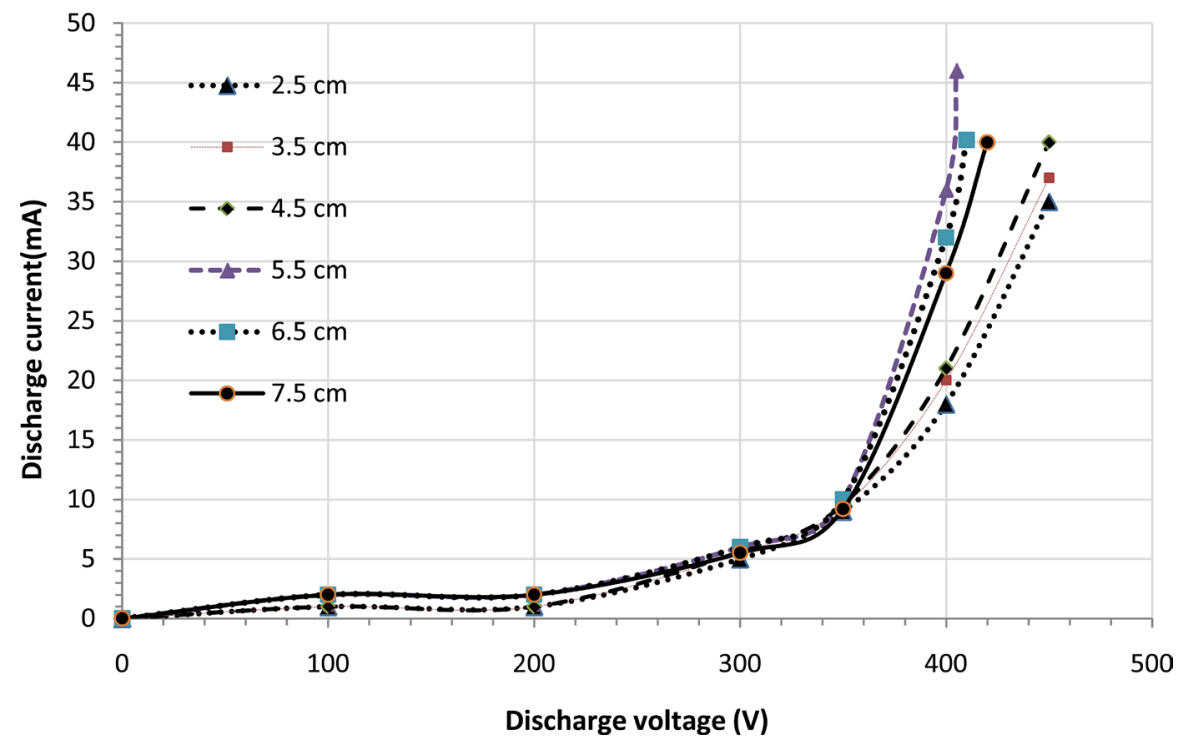

Figure 3. Current-voltage characteristics of argon gas discharge at different inter electrode distances $(2.5-7.5 \mathrm{~cm})$ and working pressure of 0.6 mbar.

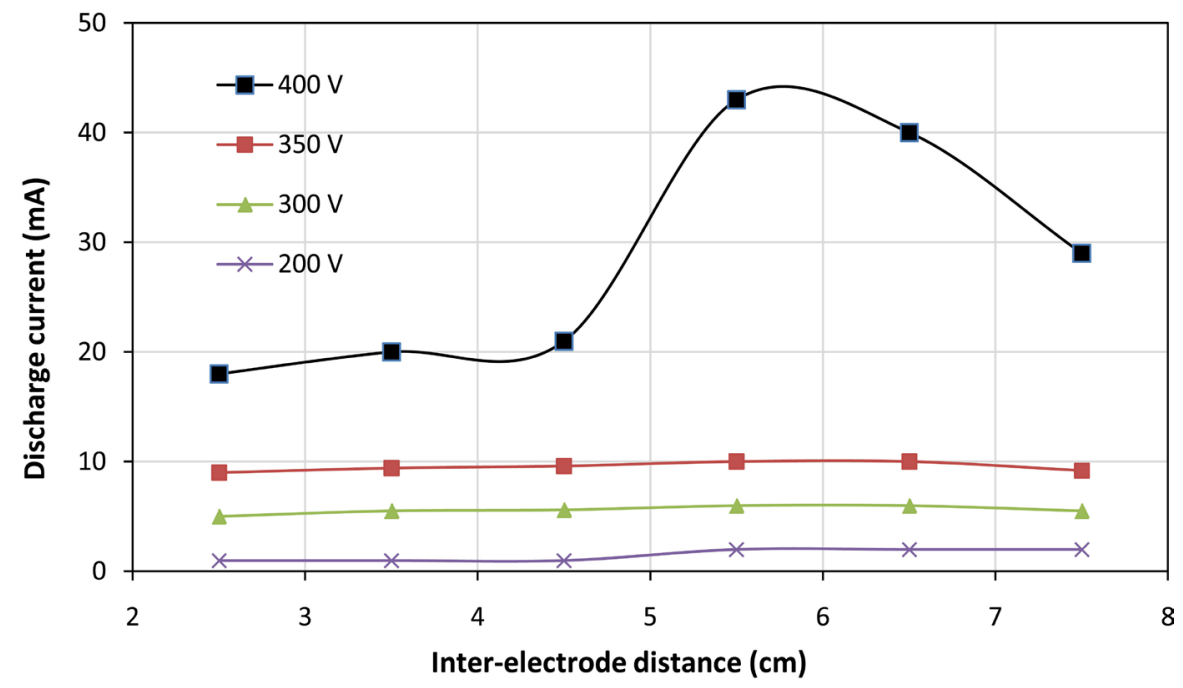

Figure 4. Variation of discharge current with inter-electrode distance at certain discharge voltages with using magnetron.

discharge voltage. This behavior is the same at all distances. At high voltages $(>350 \mathrm{~V})$, the discharge current is reasonably increased with increasing the distance, while the variation in the discharge current with distance is very small at lower voltages $(<300 \mathrm{~V})$. The electrodes are fully covered by the discharge and any increase in discharge current leads to an increase in the cathode fall. So, the voltage across the electrodes rises sharply.

Different mixing ratios of Ar: $\mathrm{N}_{2}$ are characterized to determine the optimum ratio at which the required silicon nitride will be prepared, as shown in Figure 5. It is clearly the mixing of nitrogen gas with argon at ratio $\mathrm{Ar}: \mathrm{N}_{2}$ of 1:1, an increase in the discharge current was observed, while as shown in Figure 6, at ratio Ar: $\mathrm{N}_{2}$ of 2.5:1 which increases the discharge current at the distance of $7.5 \mathrm{~cm}$. The difference is very small at low discharge voltages $(200-300 \mathrm{~V})$ because the 
major contribution of nitrogen molecules is due to the ionization by primary electrons. This difference is clearly observed at high discharge voltages $(>300 \mathrm{~V})$ because the secondary electrons are accelerated by higher electric field (V/d) and then the ionization of nitrogen molecules by collisions with these electrons is increased. Therefore, the contributions of ionized molecules are added.

In Figure 7, the Paschen's curve of argon gas discharge with magnetrons at different inter-electrode distances $(2.5-7.5 \mathrm{~cm})$ in order to determine the point at which the sputtering process is applicable. It follows from this figures, that on increasing the gap $\mathrm{d}$ the curves is shifted not only to the region of higher breakdown voltages, but simultaneously to higher $p \cdot d$ values. This shift of the breakdown curves to higher $\mathrm{V}_{\mathrm{B}}$ and $p \cdot d$ values with the increase of the inter-electrode distance $d$ is associated with the growth of the losses of charged particles on the lateral walls of the discharge tube due to the diffusion across the electric field [12].

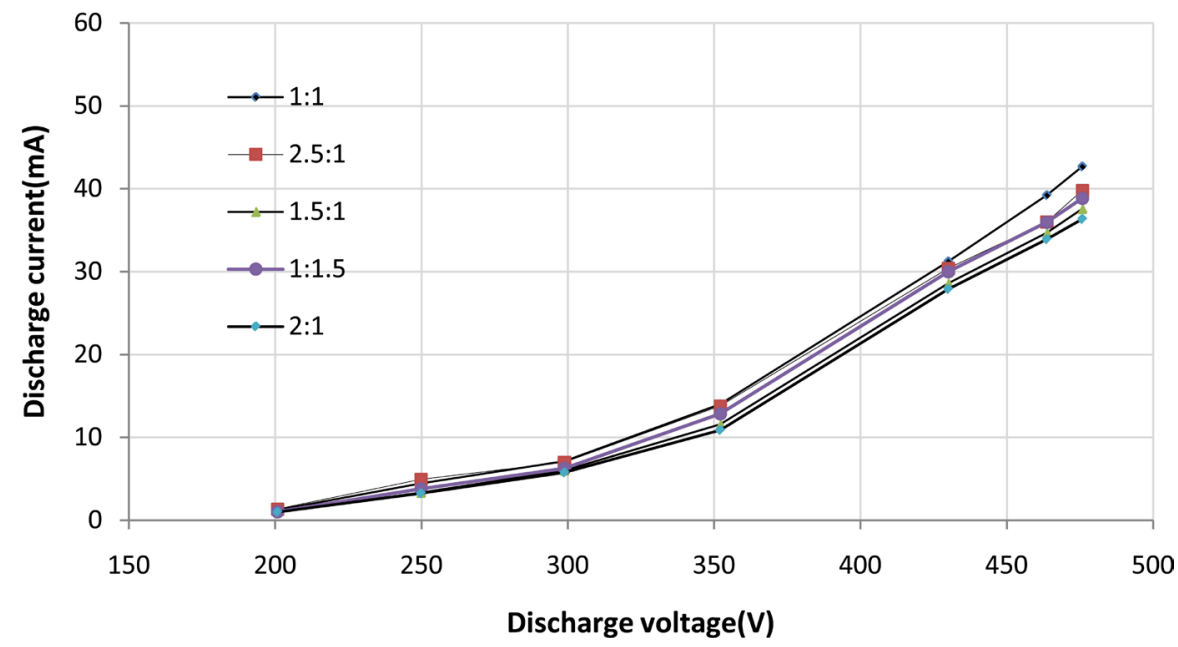

Figure 5. Discharge current-voltage characteristics for different argon/nitrogen mixtures at total gas pressure of $0.6 \mathrm{mbar}$ and inter-electrode distance of $4.5 \mathrm{~cm}$.

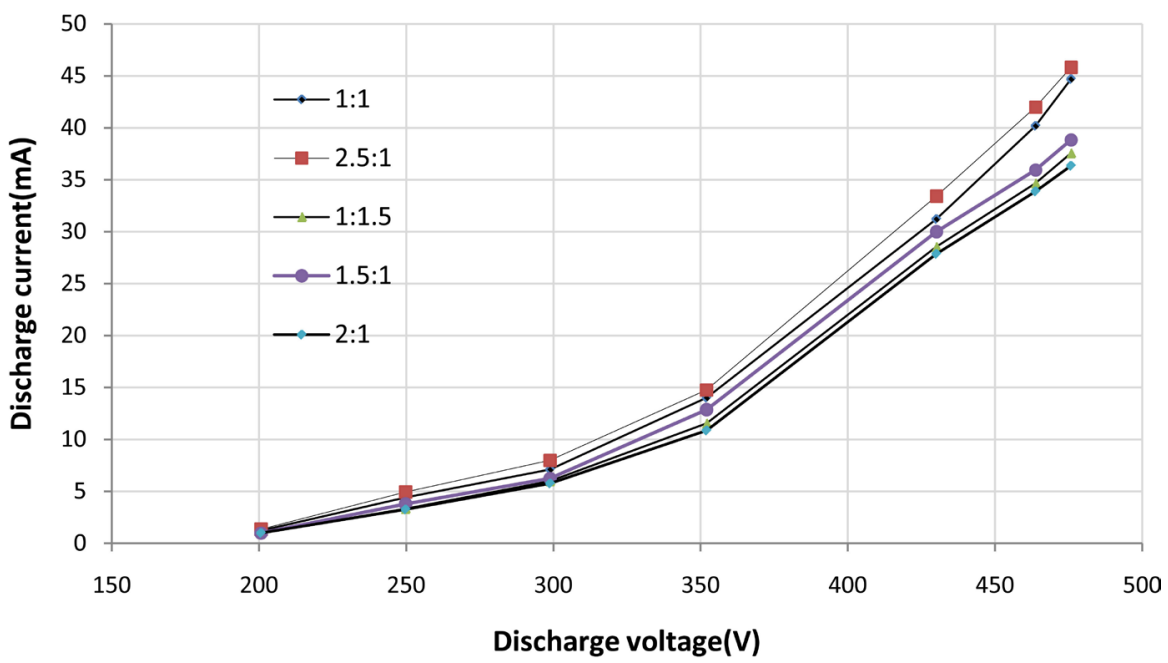

Figure 6. Discharge current-voltage characteristics for different argon/nitrogen mixtures at total gas pressure of 0.6 mbar and inter-electrode distance of $7.5 \mathrm{~cm}$. 

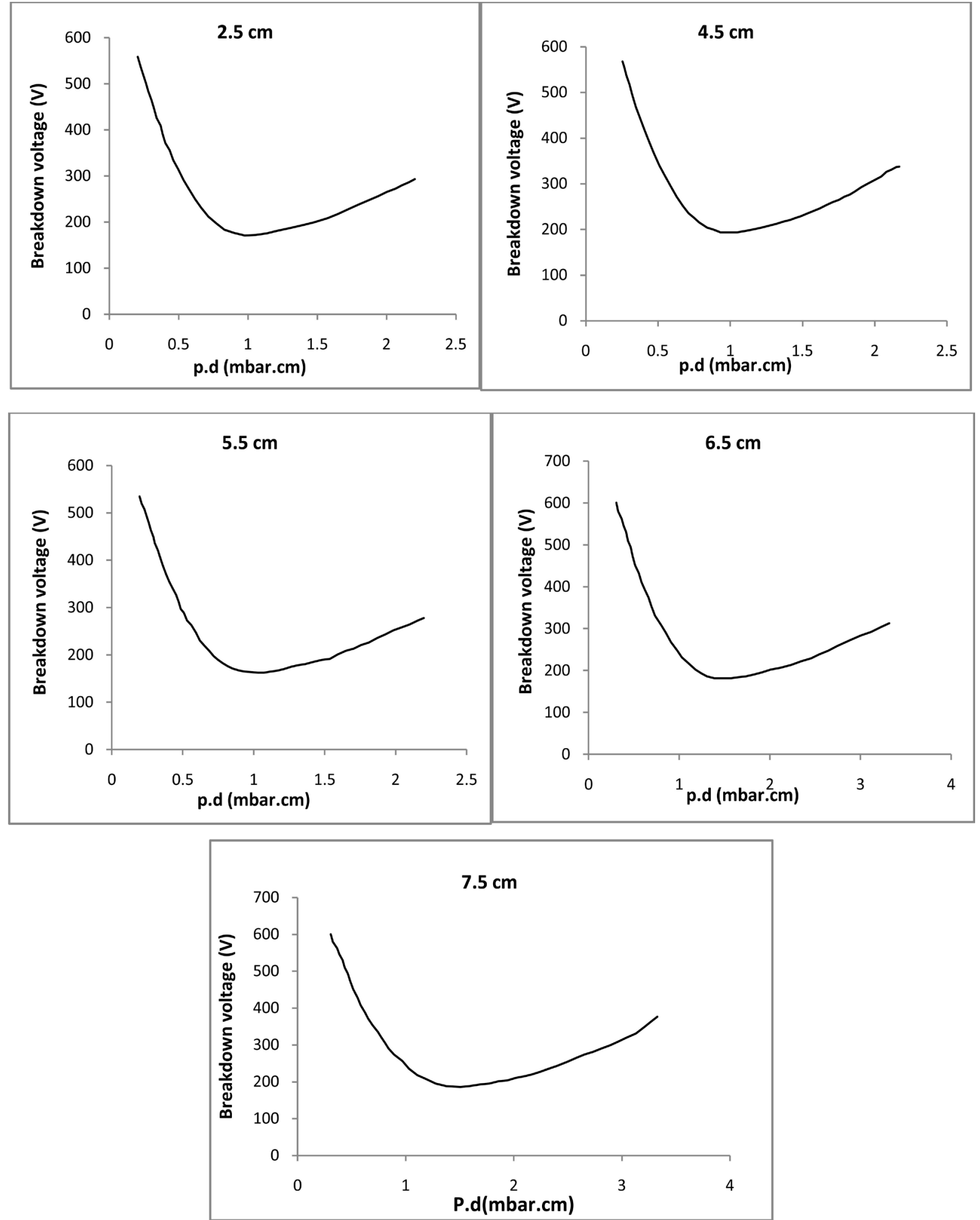

Figure 7. Paschen's curves of argon gas discharge at different inter-electrode distances $(2.5-7.5 \mathrm{~cm})$.

These results can be explained as a decrease in the collision frequency. At low gas pressure, the electron mean free path was longer and collision probability was less than that at high gas pressure, so there were few collisions. Therefore, electrons need more energy to ionize the neutral atoms. At inter-electrode dis- 
tances of 2.5 and $4.5 \mathrm{~cm}$, the Paschen's curve are approximately coincided and the minimum of p.d product is $1 \mathrm{mbar} \cdot \mathrm{cm}$, at breakdown voltages of 185 and $200 \mathrm{~V}$, respectively. At inter-electrode distances of 5.5 and $6.5 \mathrm{~cm}$, the minimum points are shifted towards higher values (1.15 and $1.5 \mathrm{mbar} \cdot \mathrm{cm})$, at breakdown voltages of 166 and $184 \mathrm{~V}$, respectively. which are not applicable in sputtering applications. This can be attributed to the higher voltages required for breakdown at larger distances. At inter-electrode distance of $7.5 \mathrm{~cm}$, the value of the breakdown voltage was increase about $196 \mathrm{~V}$. Apparently, such a shift of the breakdown curves toward higher values of $V_{B}$ and $p \cdot d$ with increasing distance (d) may be attributed to an increase in losses of charged particles on the cylindrical wall of the discharge tube. This is due to diffusion across the electric field.

The variation of the breakdown potential as a function of gas pressure at inter-electrode distance $(2.5$ and $4.5 \mathrm{~cm})$ respectively. It is clear that the breakdown voltage $V_{B}$ increases as nitrogen gas percentage $50 \%$, as shown in Figure 8 and Figure 9. This effect is due to, the additional energy loss channel nitrogen gas such as vibration, rotational and molecular dissociation, $V_{\mathrm{B}}$ abruptly was increased when the small amount of nitrogen was added. This curves was clearly shifted upward due to the presence of nitrogen molecules in the gas mixture and they require relatively high voltages for breakdown $\left(\mathrm{V}_{\min } \sim 230 \mathrm{~V}\right)$. Accordingly, the $(p \cdot d)_{\min }$ point was shifted downward to about $0.7 \mathrm{mbar} \cdot \mathrm{cm}$.

In Figure 10 shows the effect of nitrogen when the ratios of mixing $\mathrm{Ar}: \mathrm{N}_{2}$ are 2.5:1 at inter-electrode distance of $7.5 \mathrm{~cm}$. The breakdown voltage was increasing about $245 \mathrm{~V}$ and the $(p \cdot d)_{\min }$ point was shifted downward to about $0.67 \mathrm{mbar} \cdot \mathrm{cm}$.

Figure 11 and Figure 12 show the $\mathrm{Ar}$ and $\mathrm{N}_{2}$ gases discharge current as a function of working gas pressure at certain discharge voltage $(600 \mathrm{~V})$ for different inter-electrode distances. It is clearly the discharge current was varied by changing the working gas pressure. Electric field accelerates the ions and electrons which then collide elastically with atoms/molecules of working gas giving

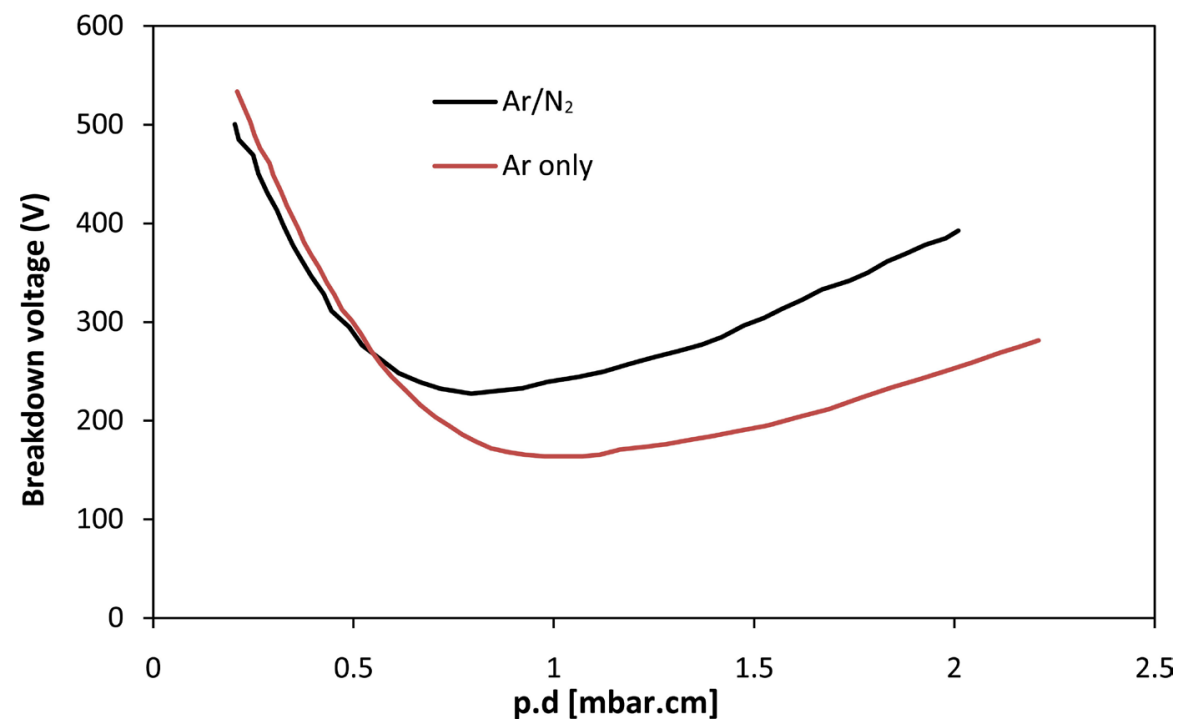

Figure 8. Paschen's curve for argon/nitrogen mixture (1:1) discharges at inter-electrode distance of $2.5 \mathrm{~cm}$. 


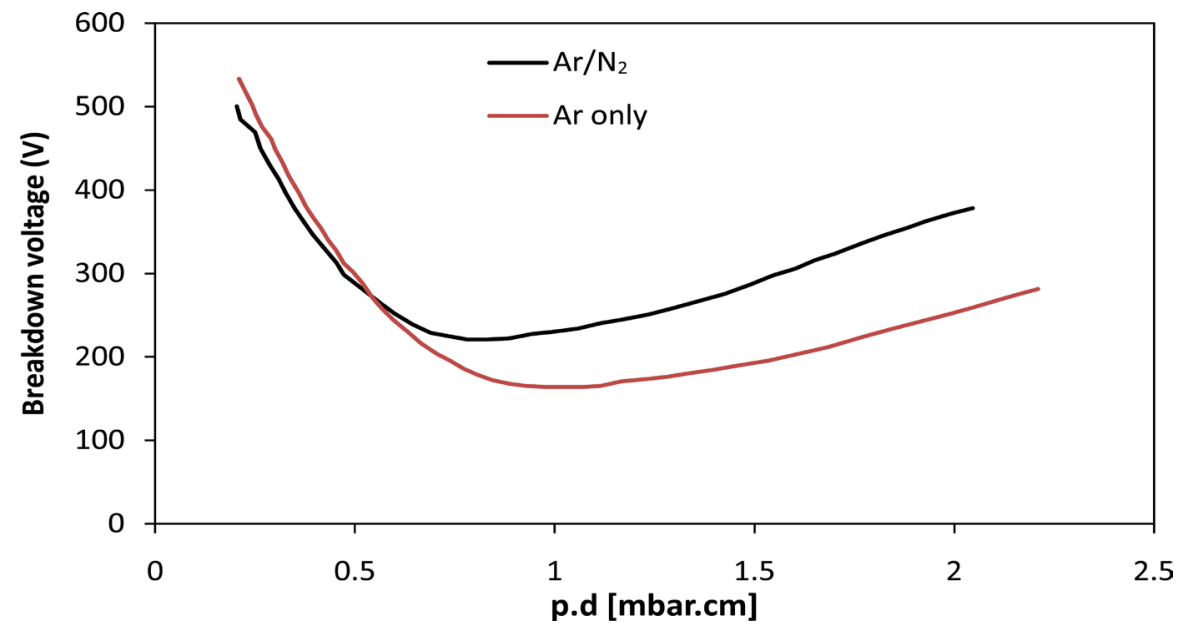

Figure 9. Paschen's curve for argon/nitrogen mixture (1:1) discharges at inter-electrode distance of $4.5 \mathrm{~cm}$.

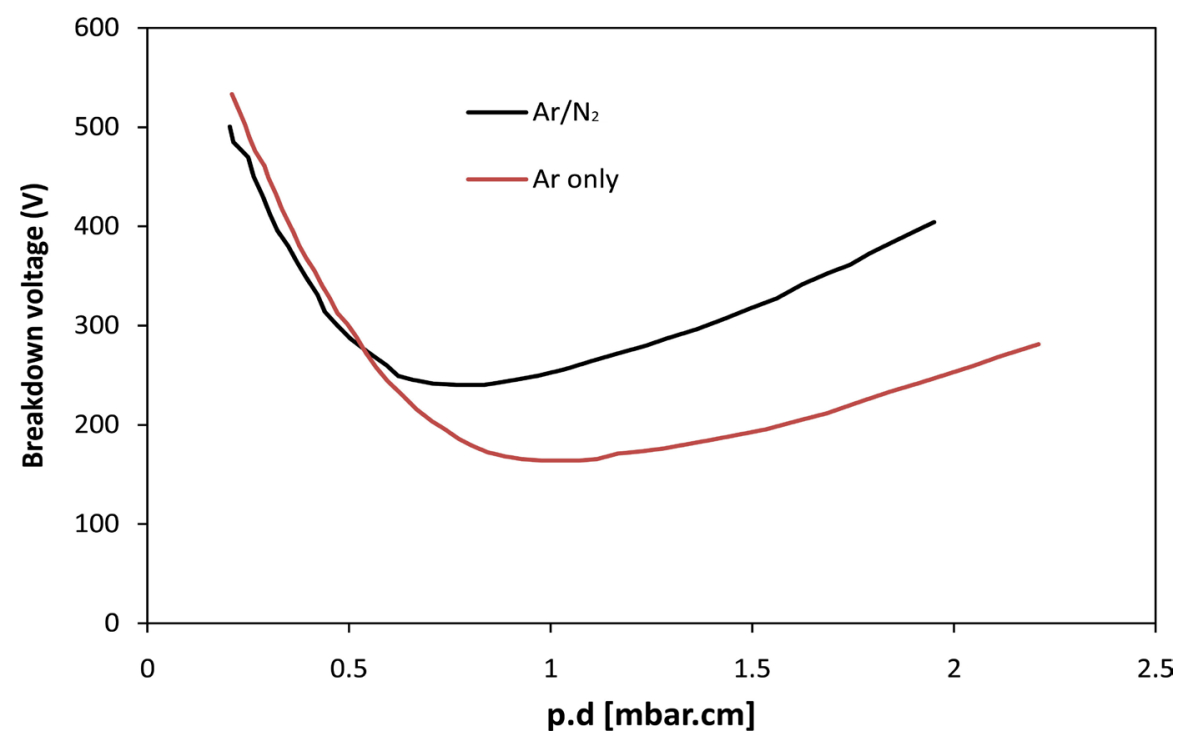

Figure 10. Paschen's curve for argon/nitrogen mixture (2.5:1) discharges at inter-electrode distance of $7.5 \mathrm{~cm}$.

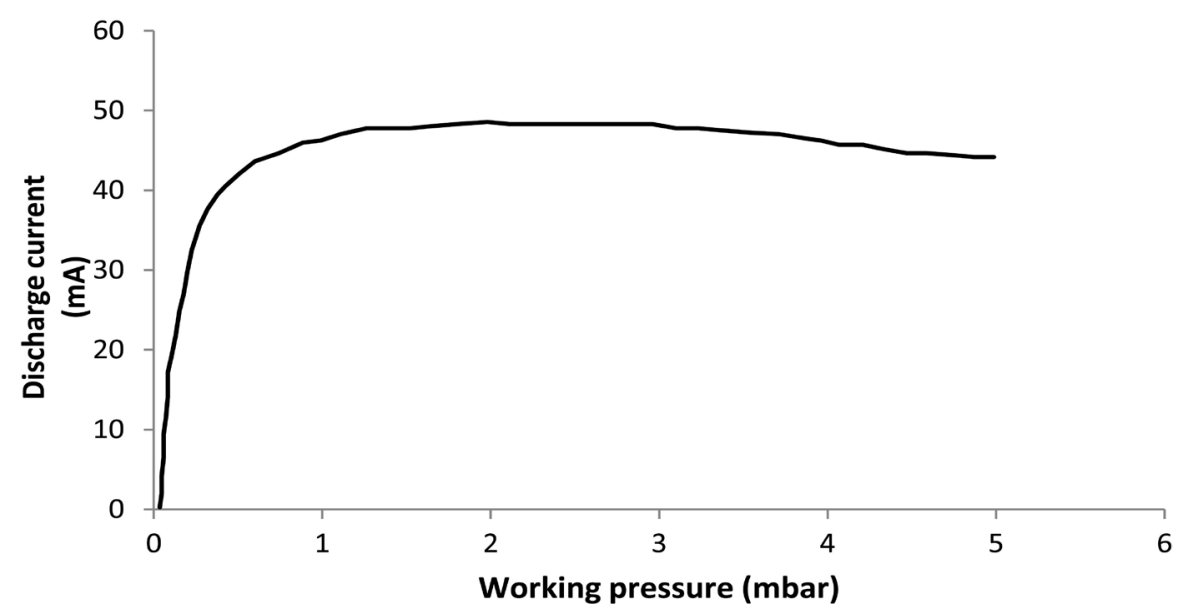

Figure 11. Variation of discharge current with working gas pressure $\left(\mathrm{Ar}_{\mathrm{N}} \mathrm{N}_{2}\right)$ at discharge voltage $(600 \mathrm{~V})$ and inter-electrode distances $2.5 \mathrm{~cm}$. 


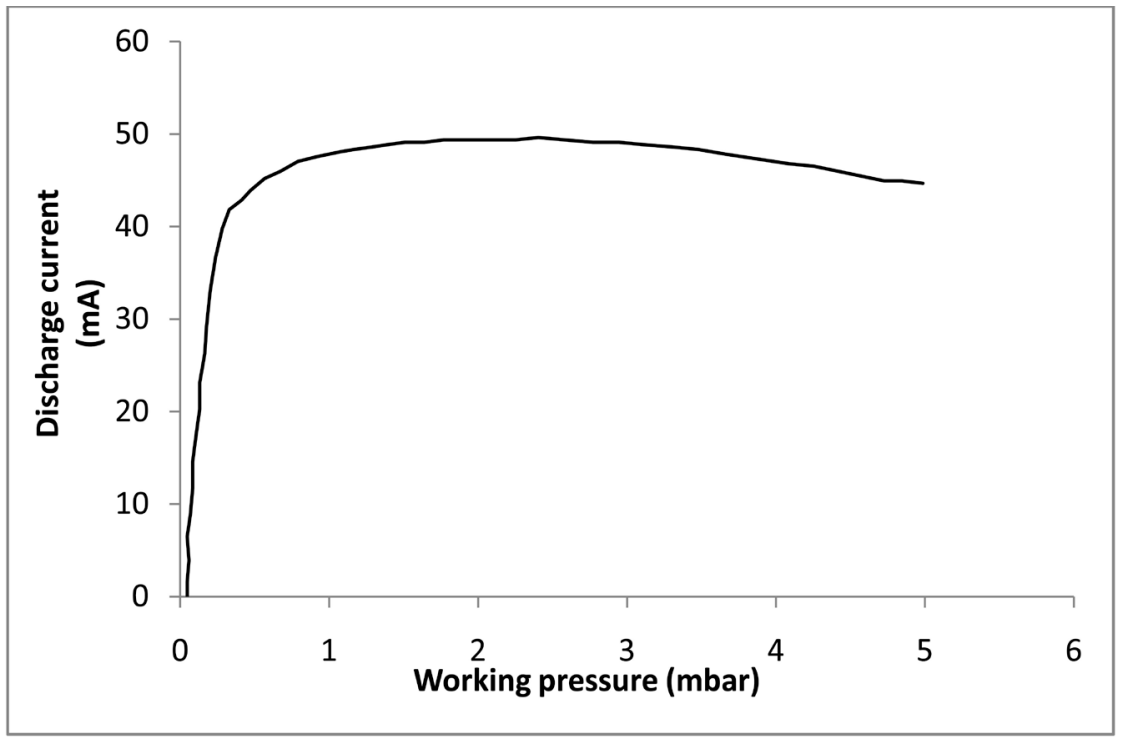

(a)

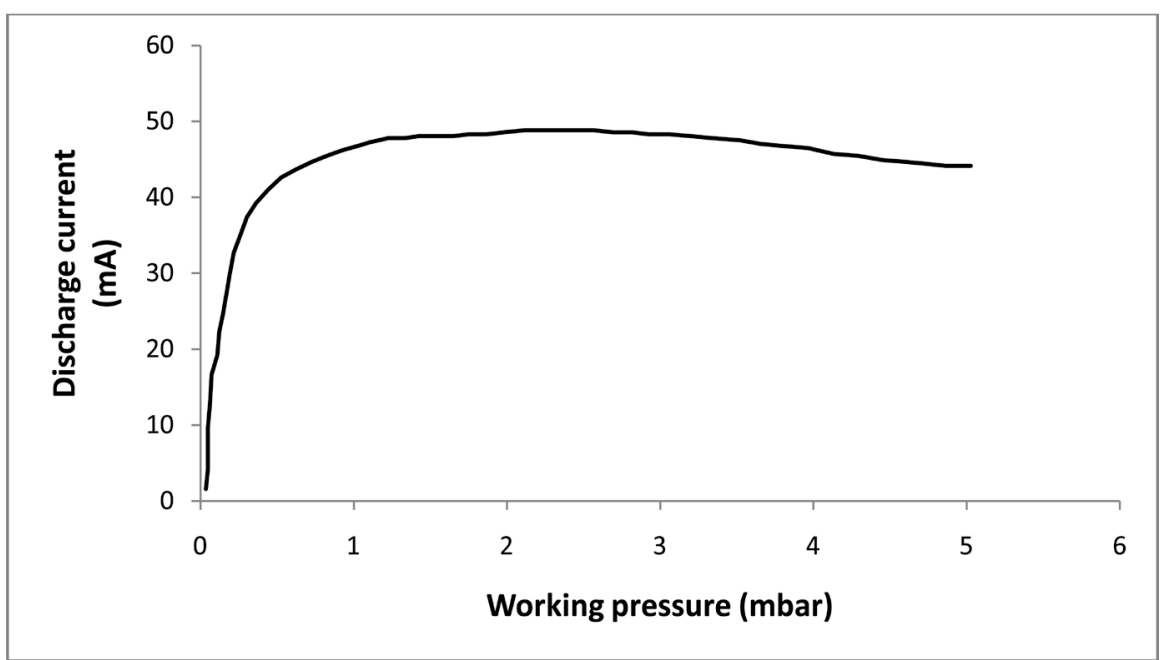

(b)

Figure 12. Variation of discharge current with working gas pressure $\left(\operatorname{Ar}: \mathrm{N}_{2}\right)$ at discharge voltage $(600 \mathrm{~V})$ and different inter-electrode distances. (a) $4.5 \mathrm{~cm}$ and (b) $7.5 \mathrm{~cm}$.

rise to discharge current [13]. With increasing of working gas pressure, which is attributed to more molecules which are available for the electrons to collide with and to generate a new free electron and a positive ion and so making the DC voltage more negative. The discharge current increase (up to $44 \mathrm{~mA}$ ) with small increase in working gas pressure. The discharge current is decreasing with increasing gas pressure above 3 mbar. The relation was plotted at certain discharge voltage of $600 \mathrm{~V}$ and three certain distances between the electrodes of $(2.5,4.5$ and $7.5 \mathrm{~cm}$ ).

\section{Conclusion}

The main results of this work can be summarized as follows: As the inter-electrode distance increased the breakdown voltage increases of range $(2.5-7.5) \mathrm{cm}$. 
By using a lab-made gas mixer unit we conclude, the addition of $\mathrm{N}_{2}$ to Ar discharge causes an increase in the values of breakdown voltage value. As we can see, the addition of gas mixer unit as a new part to the system of plasma sputtering was not confusing the characterization of plasma discharge.

\section{References}

[1] Chiad, B.T., Al-Zubaydi, T.L., Khalaf, M.K. and Khudiar, A.I. (2009) Construction and Characterization of a Low Pressure Plasma Reactor Using Glow Discharge. Journal of Optoelectronics and Biomedical Materials, 1, 255-262.

[2] Scanlan, J.V. (1991) Langmuir Probe Measurement in 13.56 MHz Discharges. Ph.D. Thesis, Dublin City University, Dublin.

[3] Naidu, M.S. and Kamaraju, V. (2009) High Voltage Engineering. 4th Edition, Tata McGraw-Hill.

[4] Khalaf, M.K. (2010) Investigation of the Interaction of Glow Discharge Plasma with Metal Surfaces. Ph.D. Thesis, University of Baghdad, Baghdad.

[5] Petraconi, G., Maciel, H.S., Pessoa, R.S., Murakami, G., Massi, M., Otani, C., Uruchi, W.M.I. and Sismanoglu, B.N. (2004) Longitudinal Magnetic Field Effect on the Electrical Breakdown in Low Pressure Gases. Brazilian Journal of Physics, 34. https://doi.org/10.1590/S0103-97332004000800028

[6] Braithwaite, N.St.J. (2000) Introduction to Gas Discharges. Plasma Sources Science and Technology, 9, 517. https://doi.org/10.1088/0963-0252/9/4/307

[7] Nasser, E. (1971) Fundamentals of Gaseous Ionization and Plasma Electronics. John Wiley \& Sons, Inc.

[8] Auday, G., Guilot, Ph., Faly, J. and Brunet, H. (1998) Experimental Study of the Effective Secondary Emission Coefficient for Rare Gases and Copper Electrodes. Journal of Applied Physics, 83, 5917.

[9] Lieberman, M.A. and Lichtenberg, A.J (1994) Principles of Plasma Discharges and Materials Processing. John Wiley \& Sons.

[10] Wadhwa, C.L. (2007) High Voltage Engineering. New Age International.

[11] Wang, J. (1960) Simulation of Gas Discharge in Tube and Paschen's Law. Optics and Photonics Journal, 3, 313-317. https://doi.org/10.4236/opj.2013.32B073

[12] Saeed, A., Khan, A.W., Shafiq, M., Jan, F., Abrar, M., Zakaulislam, M. and Zakaullah, M. (2014) Investigation of $50 \mathrm{~Hz}$ Pulsed DC Nitrogen Plasma with Active Screen Cage by Trace Rare Gas Optical Emission Spectroscopy. Plasma Science and Technology, 16, 324-328. https://doi.org/10.1088/1009-0630/16/4/05

[13] Chapman, I.B. (1980) Glow Discharge Processes: Sputtering and Plasma Etching. John Wiley \& Sons. Inc., New York. 
Submit or recommend next manuscript to OALib Journal and we will provide best service for you:

- Publication frequency: Monthly

- 9 subject areas of science, technology and medicine

- Fair and rigorous peer-review system

- Fast publication process

- Article promotion in various social networking sites (LinkedIn, Facebook, Twitter, etc.)

- Maximum dissemination of your research work

Submit Your Paper Online: Click Here to Submit

Or Contact service@oalib.com 